\title{
Hemorrhoidal Hemorrhage
}

National Cancer Institute

\section{Source}

National Cancer Institute. Hemorrhoidal Hemorrhage. NCI Thesaurus. Code C78337.

Bleeding from the hemorrhoids. 